\title{
INTERFACIAL PROPERTIES AND MECHANICAL BEHAVIOR OF TITANIUM ALUMINIDES
}

$$
\text { CONF-971201-- }
$$

M. H. YOO, C. L. FU

Metals and Ceramics Division, Oak Ridge National Laboratory, Oak Ridge, TN 37F EOUEIVED yoo@ornl.gov

ABSTRACT

OSTI

The role of various interfaces in deformation and fracture behavior of two-phase $\mathrm{TiAl}_{-} \mathrm{Ti}_{3} \mathrm{Al}$ alloys is analyzed on the basis of the specific interfacial and surface energies determined from $a b$ initio calculations. The propensity of twinning observed in these alloys is consistent with the low true-twin boundary energy. The strong plastic anisotropy reported in TiAl polysynthetically twinned (PST) crystals is attributed partly to the localized slip along lamellar interfaces, thus lowering the yield stress for soft orientations. Interfacial fracture energies are estimated to be the highest for the $\alpha_{2} / \gamma$ lamellar boundary and the lowest for the $120^{\circ}$ rotational $\gamma / \gamma$ boundary. The fracture mode mixity plays an important role in the crack-tip plasticity by ordinary slip and truetwinning, leading to translamellar and interfacial fracture.

\section{INTRODUCTION}

The majority of structural materials successfully developed and used for high-temperature structural applications are two-phase or multiphase systems. This is because interfacial structures and properties resulting from phase separation or decomposition can offer many unique microstructural advantages in thermodynamic stability, directional alignment, and dispersion of component phases. One outstanding case in point is $\gamma / \gamma^{\prime}$ two-phase single crystalline nickel-base superalloys. Recently, another intermetallics-based system which has been the focus of extensive research and development is gamma titanium aluminides $[1,2]$. In this case of titanium-rich twophase TiAl- $\mathrm{Ti}_{3} \mathrm{Al}$ alloys, significant advances have been made in understanding the role of interfaces in deformation and fracture behavior of fully lamellar microstructure, due largely to the two significant contributions: (a) controlled experimental investigations using the so-called polysynthetically twinned (PST) crystals, e.g., [3,4] and (b) interpretive and predictive capability of computational approach for bulk, defect and interfacial properties, e.g., [5,6]. It is the latter which is the focus of this paper.

The purpose of this paper is, first, to summarize the calculated results of surface and interfacial (planar faults) energies of two-phase $\mathrm{TiAl}_{\mathrm{A}} \mathrm{Ti}_{3} \mathrm{Al}$ alloys and, second, to discuss the role of interfaces in deformation and fracture of PST TiAl crystals.

\section{LAMELLAR MICROSTRUCTURE}

Formation of lamellar microstructure in gamma titanium aluminides is best described with the aid of a partial Ti-Al phase diagram [7] as shown in Fig. 1. The single-phase $\alpha$-field extends up to $1450^{\circ} \mathrm{C}$ in the near equiatomic composition. Because of this single phase field, in which aluminum is completely in solid solution with titanium of the h.c.p. structure, a variety of microstructure consisting of $\gamma$ and $\alpha_{2}$ phases can be obtained in the composition range of 43-50 at. \% Al using different cooling rates [8]. The crystal structures of $\gamma$-phase TiAl ( $\mathrm{Ll}_{0}$ type) and $\alpha_{2}$-phase $\mathrm{Ti}_{3} \mathrm{Al}$ $\left(\mathrm{DO}_{19}\right.$ type) are shown in Fig. 1. When a two-phase TiAl alloy of near-equiatomic composition is 


\section{DISCLAIMER}

This report was prepared as an account of work sponsored by an agency of the United States Government. Neither the United States Government nor any agency thereof, nor any of their employees, makes any warranty, express or implied, or assumes any legal liability or responsibility for the accuracy, completeness, or usefulness of any information, apparatus, product, or process disclosed, or represents that its use would not infringe privately owned rights. Reference herein to any specific commercial product, process, or service by trade name, trademark, manufacturer, or otherwise does not necessarily constitute or imply its endorsement, recommendation, or favoring by the United States Government or any agency thereof. The views and opinions of authors expressed herein do not necessarily state or reflect those of the United States Government or any agency thereof. 


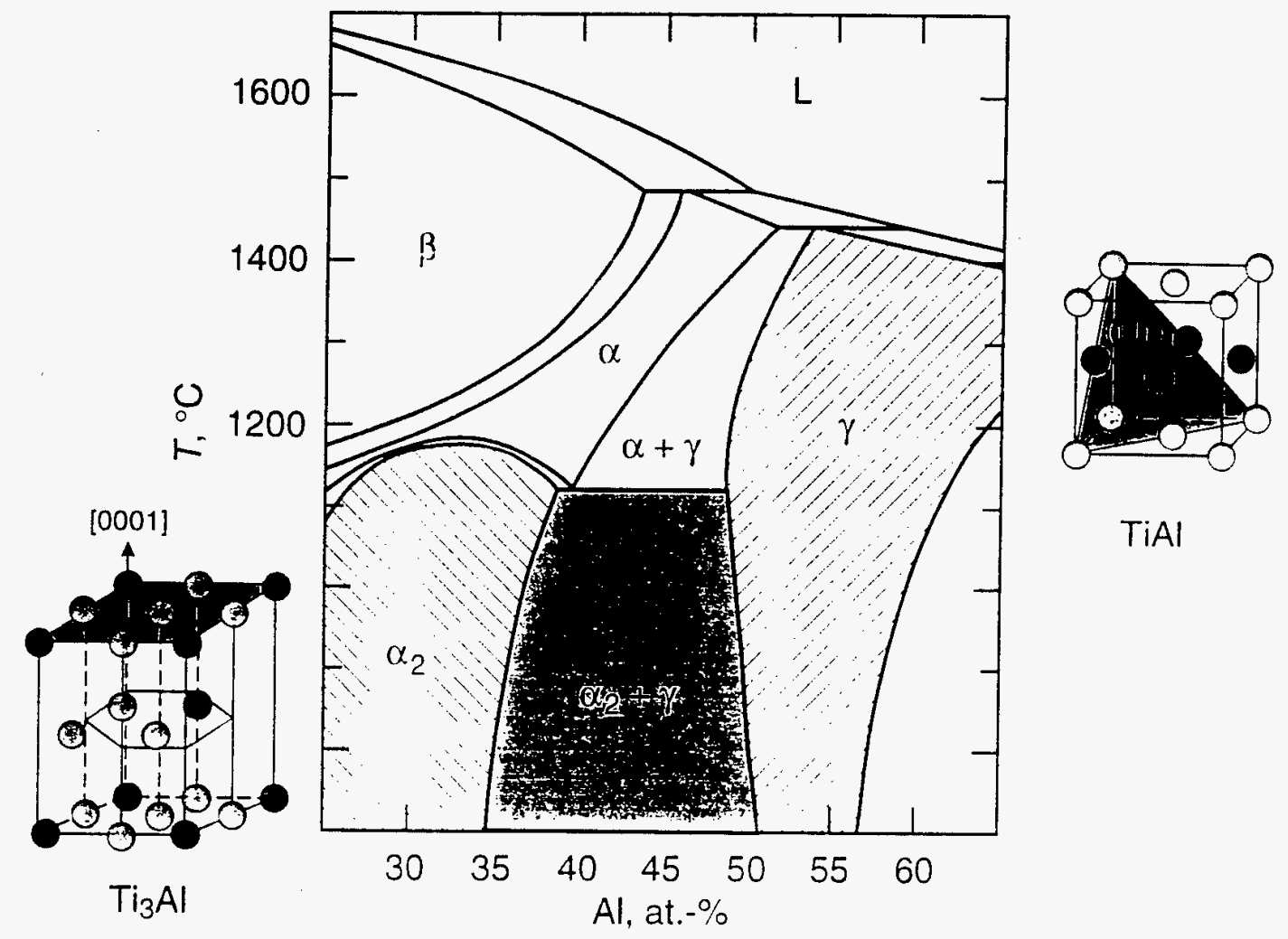

Fig. 1. A partial TiAl phase diagram and crystal structures of $\alpha_{2}$ and $\gamma$ phases

prepared by usual ingot-metallurgy methods, the $\gamma$-phase precipitates from the $\alpha$-phase producing a lamellar structure which is composed of the transformed $\gamma$ and remaining $\alpha$ lamellae. Gamma lamellae are formed in such a way that the close-packed planes and directions in the $\gamma$-phase are matched parallel to the corresponding planes and directions in the $\alpha$-phase, satisfying the so-called Blackburn relationship [9],

$$
\{111\}_{\gamma} / /(0001)_{\alpha} \quad \text { and } \quad<110>_{\gamma} / /<11 \overline{2} 0>_{\alpha} \text {. }
$$

In the near-equiatomic composition, the ordering of $\alpha \rightarrow \alpha_{2}$ usually occurs after the formation of a lamellar structure. However, nucleation and growth of $\gamma$ lamellae can be preceded by the ordering of the $\alpha$-phase when two-phase alloys with 40-44 at. \% Al are cooled from the $\alpha$ singlephase field at fairly rapid cooling rates $[10,11]$. In this case, the $\gamma$ lamellae precipitate out of the $\alpha_{2}$ matrix. In any case, whichever the sequence of transformation is, the $\gamma$ lamellae are observed to form by obeying the crystallographic habit relationship of Eq. (1). The microstructure of a PST crystal [3] is equivalent to that of a single-crystalline grain of fully lamellar polycrystals.

Figure $2(a)$ shows the atom stacking sequence of $\mathrm{ABC}$ on the (111) plane of the $\mathrm{L}_{0}$ structure viewed on the (111) plane, wherein the three different fault vectors, $\mathbf{b}_{\mathbf{i}}$, are described. Figure $2(b)$ shows schematically how three different kinds of planar faults are created at three different types of $\gamma / \gamma$ interfaces. When the angle of rotation, $\theta$, and the fault shift vector, $\mathbf{f}$, are both zero, the top and bottom halves together constitute the reference state of a single crystal, i.e., the total internal energy is set to zero.

Crystallographic descriptions for each of $\theta=60,120$. and $180^{\circ} \gamma / \gamma$ interfaces and their relative energies have been discussed by Rao et al. [12] on the basis of Bollman's O-lattice theory and an empirical Embedded Atom Method (EAM). The interfacial energies of these $\gamma / \gamma$ variants were determined from first-principles local-density-functional (LDF) calculations including atomic relaxation near the interfaces. 


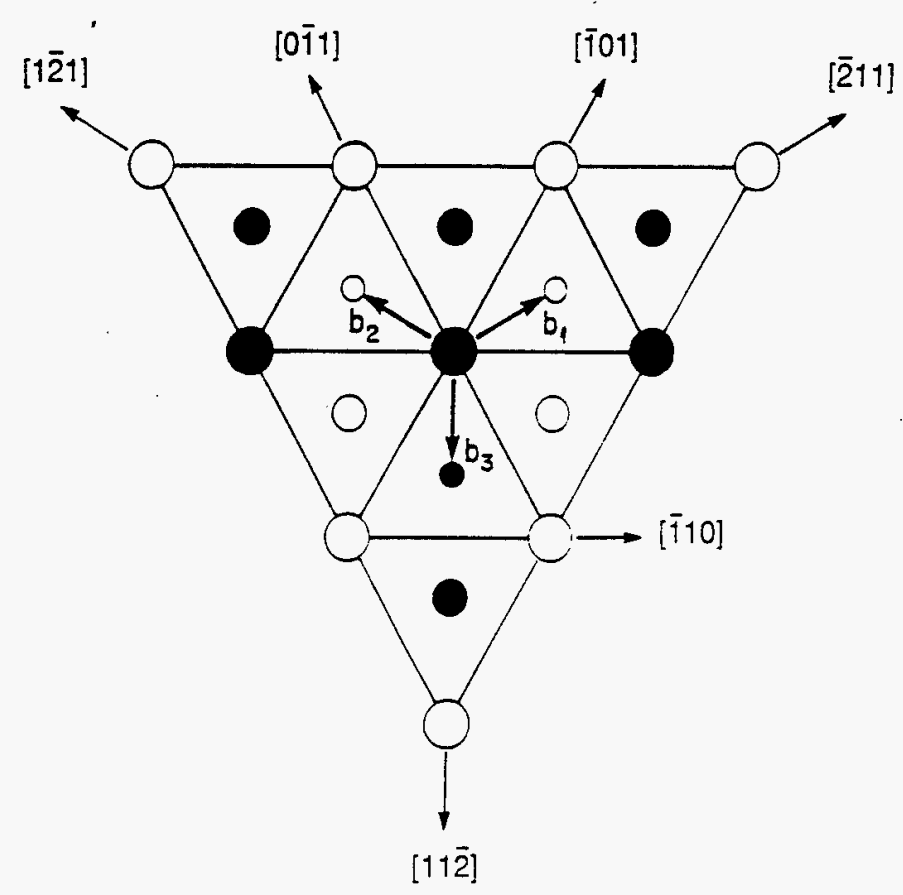

(a)

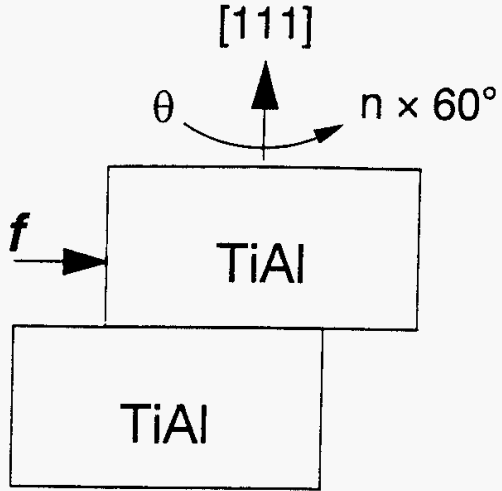

(b)

Fig. 2(a). Atomic stacking $(\mathrm{ABC})$ sequence on the (111) plane of the $\mathrm{L} 1_{0}$ structure, and $(b)$ Schematic illustration of translation and rotation operations.

\section{THEORETICAL METHODS}

The interfacial energies were determined from first-principles local-density-functional (LDF) calculations. The full-potential linearized augmented plane-wave (FLAPW) method [13] was used to solve LDF equations. There is no shape approximation to the potential and charge density. The uniqueness of these features makes it possible to determine the energetics associated with shape deformations and lattice imperfections accurately. In this case for interfaces, angular momentum components up to $l=8$ and approximately 60 plane waves per atom are used for expansion of wave functions. Relaxed structures of interfaces were optimized by calculating HellmannFeynman forces acting on the atoms.

For the calculation of $\gamma / \gamma$ lamellar interfacial energies, supercell sizes of $5 \times 5$ (i.e., repeated layer stacking sequence of 5 layers of TiAl separating the interfaces) were used. For the calculation of antiphase boundary (APB) and complex stacking fault (CSF) energies in bulk TiAl. supercell sizes with 12 and 11 layer separating adjacent interfaces were used.

\section{ENERGIES OF INTERFACES}

\section{y/y Interfaces}

All the calculated interfacial energies in Table I are the values obtained after atomic relaxation. Fault energies calculated for the three kinds on the (111) plane. i.e.. APB with $\mathbf{f}=\mathbf{b}_{1}-\mathbf{b}_{3}$ or $\mathbf{b}_{2}$ $\left.\mathbf{b}_{3}=<\overline{101}\right] / 2^{*}$, superlattice intrinsic stacking fault (SISF) with $\mathbf{f}=\mathbf{b}_{3}=[11 \overline{2}] / 6$, and CSF with

*The mixed <uvw] notation is used here to differentiate the first two indices from the third because of the tetragonality of the $\mathrm{L}_{0}$ structure. 


\begin{tabular}{lrrrrr}
\hline \multicolumn{1}{c}{$\begin{array}{c}\text { Interface } \\
\text { type }\end{array}$} & $\theta$ & $\mathbf{f}=0$ & $\left.\frac{1}{2}<\overline{1} 01\right]$ & $\frac{1}{6}[11 \overline{2}]$ & $\left.\frac{1}{6}<\overline{2} 11\right]$ \\
& & $\Gamma_{\mathrm{i}}$ & APB & SISF & CSF \\
\hline Bulk & $0^{\circ}$ & 0 & 560 & 90 & 410 \\
Pseudo-twin & $60^{\circ}$ & 270 & 270 & 270 & 270 \\
$\begin{array}{l}\text { Rotational } \\
\text { True-twin }\end{array}$ & $120^{\circ}$ & 250 & 250 & 280 & 280 \\
& $180^{\circ}$ & 60 & 550 & 60 & 550 \\
\hline
\end{tabular}

$\mathbf{f}=\mathbf{b}_{1}$ or $\mathbf{b}_{2}=\langle\overline{2} 11] / 6$, are listed in the first row $(\theta=0)$. In the APB, SISF, and true-twin boundary energies of $E_{\mathrm{APB}}=560, \mathrm{E}_{\mathrm{SISF}}=90$, and $\Gamma_{\mathrm{T}}=60 \mathrm{~mJ} / \mathrm{m}^{2}$ reported earlier [5], the relaxation effect was included only for the APB. Since there is no change in the nearest-neighbor atomic coordination at the SISF, superlattice extrinsic stacking fault (SESF), and true-twin interfaces, atomic relaxation at these fault interfaces is assumed to be negligibly small. The more refined recent calculation [14] gives an APB energy which is slightly increased from the previously reported value. With the inclusion of relaxation energy, the CSF energy is reduced from $\mathrm{E}_{\mathrm{CSF}}=$ $500 \mathrm{~mJ} / \mathrm{m}^{2}$ to $410 \mathrm{~mJ} / \mathrm{m}^{2}$. Woodward et al [15] reported from their LDF calculations with the layered Korringa Kohn Rostoker (LKKR) method that $\mathrm{E}_{\mathrm{APB}}, \mathrm{E}_{\mathrm{CSF}}, \mathrm{E}_{\mathrm{SISF}}$, and $\mathrm{E}_{\mathrm{SESF}}$ energies are $670,280,110$, and $110 \mathrm{~mJ} / \mathrm{m}^{2}$, respectively.

Interfacial energies for the three different types, i.e., pseudo-twin $\left(\theta=60^{\circ}\right)$, "rotational" $(\theta=$ $\left.120^{\circ}\right)$, and true-twin $\left(\theta=180^{\circ}\right)$ boundaries. are listed in the first column $(\mathbf{f}=0)$ of Table I. The pseudo-twin boundary energy of $\Gamma_{\mathrm{P}}=300 \mathrm{~mJ} / \mathrm{m}^{2}$ [16] is reduced to $270 \mathrm{~mJ} / \mathrm{m}^{2}$ after relaxation. At the pseudo-twin $\left(\theta=60^{\circ}\right)$ and rotational $\left(\theta=120^{\circ}\right)$ boundaries, while both $\mathrm{E}_{\mathrm{APB}}$ and $\mathrm{E}_{\mathrm{CSF}}$ are reduced markedly, by factors of about two, as compared to those in the bulk, $E_{\text {SISF }}$ is increased by a factor of three. At the true-twin boundary, on the other hand, changes in the fault energies are relatively small, with slight increases in both $\mathrm{E}_{\mathrm{APB}}$ and $\mathrm{E}_{\mathrm{CSF}}$ and a decrease in $\mathrm{E}_{\mathrm{SISF}}$. These values are consistent with more frequent observation of true-twin type lamellar interfaces, in two-phase TiAl alloys of binary compositions, compared with the pseudo-twin and rotational types.

Degeneracies of fault energies noted in Table I are due to geometrically equivalent characteristic patterns of interfaces resulting from certain combinations of rigid-body translations and rotations according to the O-lattice theory [12]. An example of these degeneracies can be described with the aid of Fig. 3, where the C-layer of atoms have been rotated and translated with reference to the Blayer. Figure $3(b)$ shows the geometric pattern of interfaces by $\theta=60^{\circ}$ and $\mathbf{f}=0$, and Fig. 3(c) shows that by $\theta=60^{\circ}$ and $\mathbf{f}=\mathbf{b}_{2}$. These two operations result in a geometrically equivalent pattern between two atomic rows of the adjacent $B$ and $C$ layers. Because of the assumption that $\mathrm{c} / \mathrm{a}=1$, the magnitude of $\mathbf{b}_{1}=\mathbf{b}_{2}$ are equal to that of $\mathbf{b}_{3}$, and the atomic lattices shown in Figs. 2 and 3 are equilateral triangles. With the actual value of $\mathrm{c} / \mathrm{a}=1.02$ for $\gamma$-TiAl, this symmetry and the degeneracies are broken, thus giving rise to long-range coherency stresses and interfacial dislocations to accommodate the misfit strain across the interface.

\section{$\underline{\alpha_{2} / \gamma \text { Interface }}$}

At the coherent part of an $\alpha_{2} / \gamma$ interface with the crystallographic habit relationship of (0001) [1 $1 \overline{2} 0]-\mathrm{Ti}_{3} \mathrm{Al}$ and (111)[1 $\left.\overline{1} 0\right]$ TiAl, the interfacial energy is calculated to be $100 \mathrm{~mJ} / \mathrm{m}^{2}$ (the reference energy in this case is the sum of TiAl and $\mathrm{Ti}_{3} \mathrm{Al}$, bulk energies). Significant reductions of $E_{A P B}$ and $E_{C S F}$ in $\alpha_{2}$ phase to those ( 280 and $220 \mathrm{~mJ}^{2} \mathrm{~m}^{2}$, respectively) at the $T i_{3} \mathrm{Al} / \mathrm{TiAl}$ interface were reported recently [17], which are summarized in Table II. 


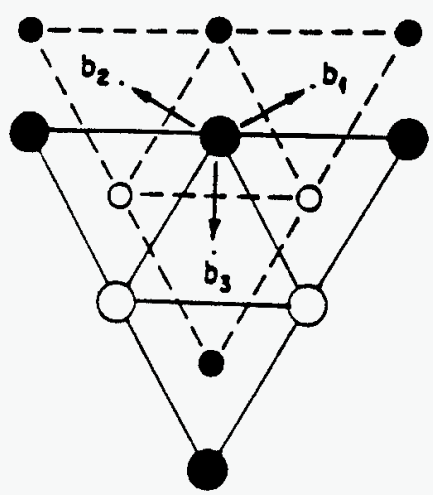

(a)

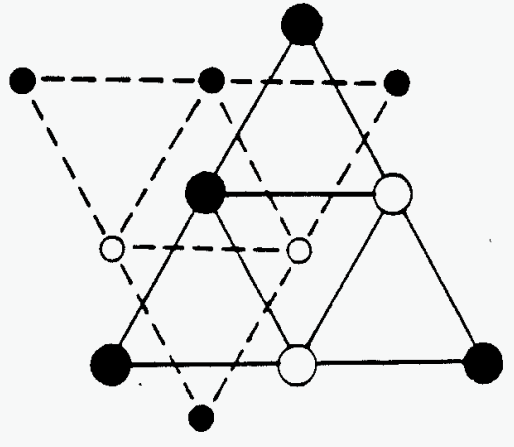

(b)

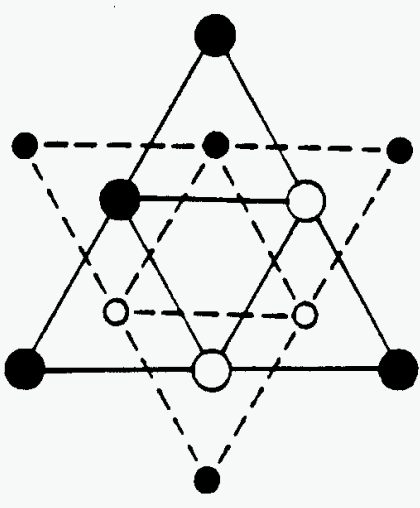

(c)

Fig. 3. Degeneracy of the shear faults at a pseudo-twin interface: $(a)$ reference state,

(b) $\theta=60^{\circ}, \mathbf{f}=0$, and (c) $\theta=60^{\circ}, \mathbf{f}=\mathbf{b}_{2}$.

Table II. Calculated Shear Fault Energies at the TiAl/Ti ${ }_{3} \mathrm{Al}$ Interface (in Units of $\mathrm{mJ} / \mathrm{m}^{2}$ )

\begin{tabular}{|c|c|c|c|}
\hline Plane & $\mathrm{APB}$ & SISF & $\mathrm{CSF}$ \\
\hline $\begin{array}{l}\text { (111) TiAl } \\
(0001) \mathrm{Ti}_{3} \mathrm{Al} \\
\text { TiAl/Ti } \mathrm{i}_{3} \mathrm{Al}\end{array}$ & $\begin{array}{l}560 \\
300 \\
280\end{array}$ & $\begin{array}{l}90 \\
20\end{array}$ & $\begin{array}{l}410 \\
320 \\
220\end{array}$ \\
\hline
\end{tabular}

\section{SHEAR FAULT ENERGIES AND DEFORMATION MODES}

$\underline{\text { TiAl }}$

Plastic deformation of $\gamma$-TiAl by slip or twinning occurs primarily on $\{111\}$ planes. An ordinary dislocation is expected to dissociate into a pair of Shockley partials, with Burgers vectors of $\mathbf{b}_{1}=[\overline{2} 11] / 6$ and $-\mathbf{b}_{2}=[\overline{1} 2 \overline{1}] / 6$, forming a strip of CSF ribbon,

$$
[\overline{1} 10] / 2 \rightarrow[\overline{2} 11] / 6+\mathrm{CSF}+[\overline{1} 2 \overline{1}] / 6 .
$$

The four-fold dissociation of a superdislocation consists of two sets of $\mathbf{b}_{3}=[11 \overline{2}] / 6$ and $-\mathbf{b}_{2}=[\overline{1} 2 \overline{1}] / 6$ partial dislocations,

$$
[01 \overline{1}] \rightarrow[11 \overline{2}] / 6+\mathrm{SISF}+[\overline{1} 2 \overline{1}] / 6+\mathrm{APB}+[11 \overline{2}] / 6+\mathrm{CSF}+[\overline{1} 2 \overline{1}] / 6 .
$$

Equilibrium widths of these two types of dislocation dissociation were determined [6] by using the calculated fault energies (Table I) and the calculated elastic constants [5]: $\mathrm{w}_{C}=0.29 \mathrm{~nm}$ (screw) or $0.50 \mathrm{~nm}$ (edge) for Eq. (2), and $\mathrm{w}_{1}=5.2 \mathrm{~nm}, \mathrm{w}_{\mathrm{A}}=0.4 \mathrm{~nm}$, and $\mathrm{w}_{\mathrm{C}}=0.66 \mathrm{~nm}$ for SISF, APB, and CSF in Eq. (3), respectively, when the [011] superdislocation is in screw orientation. 
The widths of an ordinary dislocation, Eq. (2), are still below the resolution limit of the conventional TEM technique and are in reasonable agreement with the atomistic simulation result of dislocation core spreading using the EAM [17]. The dissociation configuration of a screw superdislocation, Eq. (3), is asymmetric $\left(\mathrm{w}_{\mathrm{I}}=5.2 \mathrm{~nm}\right.$ and $\left.\mathrm{w}_{\mathrm{C}}=0.66 \mathrm{~nm}\right)$ because of the disparity between $E_{\text {SISF }}=90 \mathrm{~mJ} / \mathrm{m}^{2}$ and $E_{\mathrm{CSF}}=410 \mathrm{~mJ} / \mathrm{m}^{2}$. When a resolved shear stress is such that the leading partial dislocation in Eq. (3) is to extend the SISF ribbon further from the equilibrium width, this offers one possible dislocation mechanism for twin formation [6].

Crystallographic elements of true-twinning in TiAl by deformation are shown in Fig. 4. Deformation twinning occurs in the $\mathrm{L} 1_{0}$ structure by motion of twinning dislocations with $\mathbf{b}_{\mathbf{3}}=$ $[11 \overline{2}] / 6$ on successive (111) planes. The coherent twin boundary created by homogeneous shear process (Fig. 4) is equivalent to the true-twin interface obtained by $\mathbf{f}=0$ and $\theta=180^{\circ}$ (Fig. 2). Therefore, the twin boundary energy of $\Gamma_{\mathrm{T}}=60 \mathrm{~mJ} / \mathrm{m}^{2}$ applies equally to the coherent part of a twin boundary formed by deformation twinning.

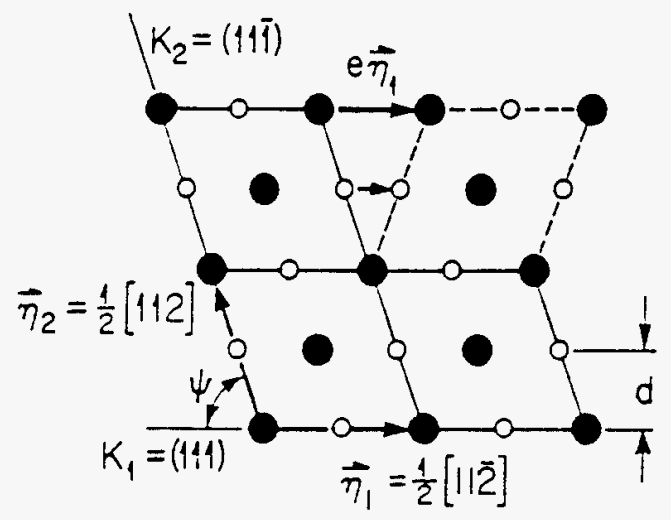

Fig. 4. Crystallography of deformation twinning in $\gamma$-TiAl. The filled circles (Ti atoms) are on the (110) plane of shear, and the open circles ( $\mathrm{Al}$ atoms) are on the adjacent plane.

$\underline{T_{3}} \underline{\underline{A l}}$

Plastic deformation of $\alpha_{2}-\mathrm{Ti}_{3} \mathrm{Al}$ of the $\mathrm{DO}_{19}$ structure is known to occur by three slip systems, viz.. the prism slip, $\{1 \overline{1} 00\}<11 \overline{2} 0>$, the basal slip, $(0001)<11 \overline{2} 0>$, and the pyramidal slip, $\{11 \overline{2} 1\}<1 \overline{1} \overline{6}\rangle$. On the (0001) basal plane, a superdislocation of Burgers vector, $\mathbf{a}=\langle 11 \overline{2} 0\rangle / \overline{3}$, is dissociated into two superpartials with Burgers vector, $\mathbf{b}=\mathbf{a} / 2=\mathbf{f}$, and each superpartial further splits into a pair of Shockley partials such that the following four-fold dissociation may occur,

$$
[11 \overline{2} 0] / 3 \rightarrow[10 \overline{1} 0] / 6+\mathrm{CSF}+[01 \overline{1} 0] / 6+\mathrm{APB}+[10 \overline{1} 0] / 6+\mathrm{CSF}+[01 \overline{1} 0] / 6
$$

Table 3 lists the shear fault energies of $\mathrm{Ti}_{3} \mathrm{Al}$ determined based on the LDF calculation [18]. In the case of (1100) prism planes, there are two different corrugated layers of atomic planes to be considered [19], and a lattice shift by the fault vector, $\mathbf{f}=[1120] / 6$, creates two distinct APBs, viz., APB-I and APB-II in Table III, by

$$
[11 \overline{2} 0] / 3 \rightarrow[11 \overline{2} 0] / 6+\mathrm{APB}+[11 \overline{2} 0] / 6 .
$$

The difference between the two APB energies for the (1100) plane listed in Table III is due to the fact that the introduction of an APB-I does not alter the nearest-neighbor coordination number of atoms at the APB interface. On the (11/21) pyramidal plane. two possible fault vectors are $\mathbf{f}_{1}=$ $\left[1 \overline{100]} / 2\right.$ and $\mathbf{f}_{2}=[1 \overline{126}] / 6$. Nevertheless, they give rise to the same APB energy of $293 \mathrm{~mJ} / \mathrm{m}^{2}$ (Table 3). Therefore, a $2 \mathbf{c}+\mathbf{a}=[1 \overline{1} \overline{2} \overline{6}] / 3$ type superdislocation is dissociated into two superpartials of $\mathbf{b}=\mathbf{c}+\mathbf{a} / 2=\mathbf{f}_{2}$ type on the (11/21) plane by 


$$
[11 \overline{2} \overline{6}] / 3-->[11 \overline{2} \overline{6}] / 6+\mathrm{APB}+[11 \overline{2} \overline{6}] / 6,
$$

and each superpartial may undergo a further splitting by either a dissociation or a decomposition.

Table III. Calculated APB and CSF Energies of $\mathrm{Ti}_{3} \mathrm{Al}$ in Units of $\mathrm{mJ} / \mathrm{m}^{2}$

\begin{tabular}{|c|c|c|c|c|}
\hline \multicolumn{2}{|c|}{$(0001)$} & \multicolumn{2}{|c|}{$(1 \overline{1} 00)$} & \multirow{2}{*}{$\frac{(11 \overline{2} 1)}{\text { APB }}$} \\
\hline$\overline{\mathrm{APB}}$ & $\mathrm{CSF}$ & $\overline{\text { APB-I }}$ & $\overline{\text { APB-II }}$ & \\
\hline 300 & 320 & 133 & 506 & 293 \\
\hline
\end{tabular}

The equilibrium widths of two-fold dissociation. Eq. (5), on the (0001) plane, with $E_{A P B}=300$ $\mathrm{mJ} / \mathrm{m}^{2}$ are only $3 \mathrm{~nm}$ and $8 \mathrm{~nm}$, respectively, for screw and edge orientations [6]. As listed in Table II. $\mathrm{E}_{\text {CSF }}$ is reduced by $31 \%$ from 320 to $220 \mathrm{~mJ} / \mathrm{m}^{2}$. This indicates that the mobility of a Shockley partial pair, Eq. (4), is increased at or near the $\alpha_{2} / \gamma$ interface.

\section{ROLE OF INTERFACES IN MECHANICAL BEHAVIOR}

Deformation and microcracking characteristics of $\gamma-\mathrm{TiAl}$ and $\alpha_{2}-\mathrm{Ti}_{3} \mathrm{Al}$ have been reviewed recently [6]. In TiAl the habit planes of slip, twinning, and microcracking are common closepacked $\{111\}$ planes. In $\mathrm{Ti}_{3} \mathrm{Al}$, plastic deformation can occur by $\{1100\}$ prismatic. (0001) basal, and pyramidal slip systems. Deformation twinning is rarely observed in $\mathrm{Ti}_{3} \mathrm{Al}$. Figure 5 shows a schematic drawing of a PST crystal. where the angle 0 is between the lamellar habit planes, $(111)_{\gamma}\left((0001)_{\alpha 2}\right.$, and the applied stress axis. In reference to the (111) plane, there are a total of six different orientations (including opposite directions) of $\gamma$ lamellae, only three crystallographic variants of I, II, and III are indicated in Fig. 5.

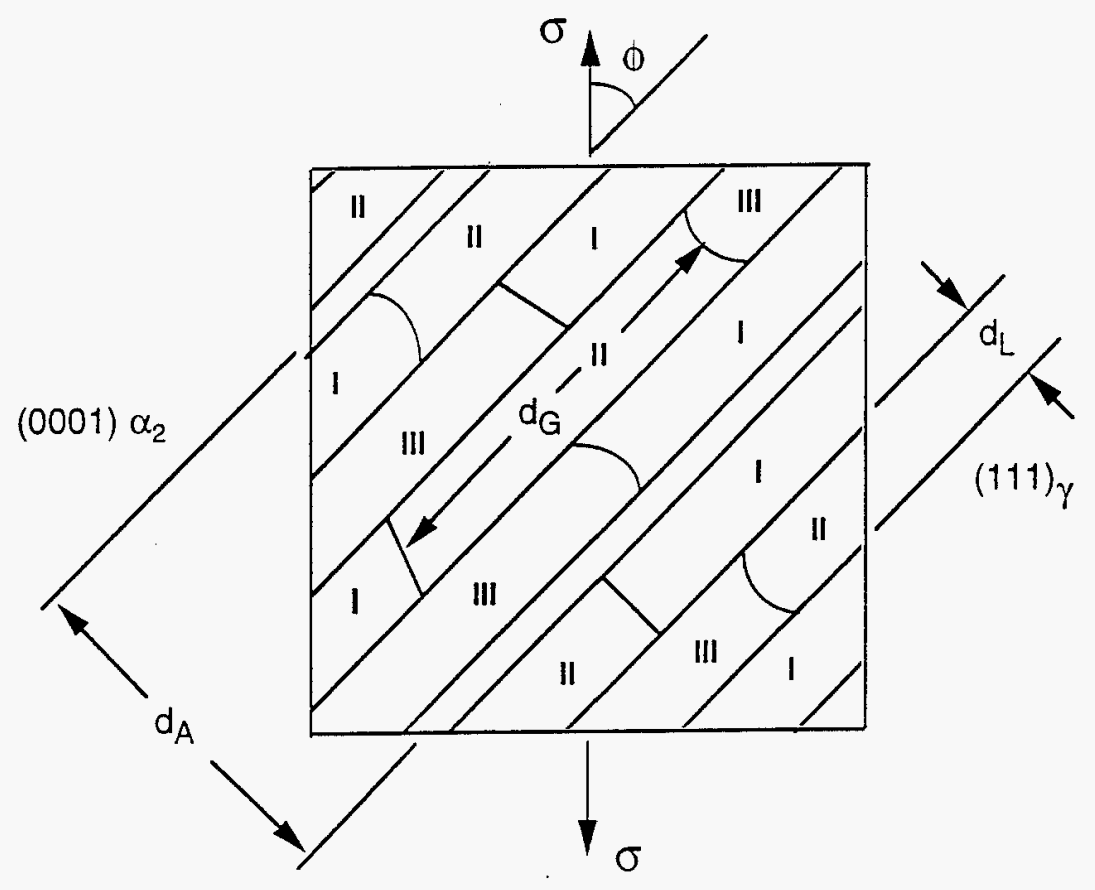

Fig. 5. Schematic microstructural description of a PST crystal. 
Experimental findings and theoretical analyses on how these interfaces affect deformation and fracture behavior of PST crystals are many [1,2], and also abundant are the records of alloy design efforts to try to obtain an acceptable balanced mechanical properties by tailoring this lamellar microstructure. In the remainder of this paper, we will discuss a few issues based on the results of first-principles calculations.

\section{Elastic Inhomogeneity}

Assuming that a bimaterial system of $\mathrm{TiAl}-\mathrm{Ti}_{3} \mathrm{Al}-\mathrm{TiAl}$ as shown in Fig. 6 is composed of two elastically isotropic phases and using the calculated elastic moduli [6], one can estimate the magnitude of internal stresses due to the elastic incompatibility [20]. The induced stress in the $\alpha_{2}$ lamella was estimated to be $-9 \%$ of an applied stress when the stress axis is perpendicular to the interfaces ([111] in Fig. 6) and $+4 \%$ when the stress is applied in the parallel direction ([1 $\overline{1} 2]$ in Fig. 6). Since the yield stresses of PST crystals at room temperature are about 300 and $500 \mathrm{MPa}$ [3] at two different hard orientations $\left(\phi=0\right.$ and $\left.90^{\circ}\right)$, the elastically induced stresses within the $\alpha_{2}$ lamellae are at most $45 \mathrm{MPa}$. This magnitude is relatively small compared to internal stresses caused by other sources, such as coherency stresses due to the lattice parameter mismatch and thermoelastic stresses due to the difference in thermal expansion. For instance, including the tetragonality of TiAl, Hazzledine et al. [21] estimated very large elastic stresses $(\approx 1 \mathrm{GPa})$ at coherent $\alpha_{2} / \gamma$ interfaces. Appel and Wagner [22] observed generation of dislocations from lamellar interfaces during in situ TEM heating cycle of $300 \rightarrow 994 \rightarrow 300 \mathrm{~K}$. The magnitude of internal stress for the dislocation generation is estimated to $140 \mathrm{MPa}$ if one assumes the difference in thermal expansion coefficients [6] between $\gamma$ and $\alpha_{2}$ phases to be $20 \%$. These internal stresses are much larger than the induced stresses due to the elastic incompatibility. Therefore, the elastic inhomogeneity between anisotropic $\gamma / \gamma$ interfaces and the $\alpha_{2} / \gamma$ boundary will be neglected in the ensuing discussion.

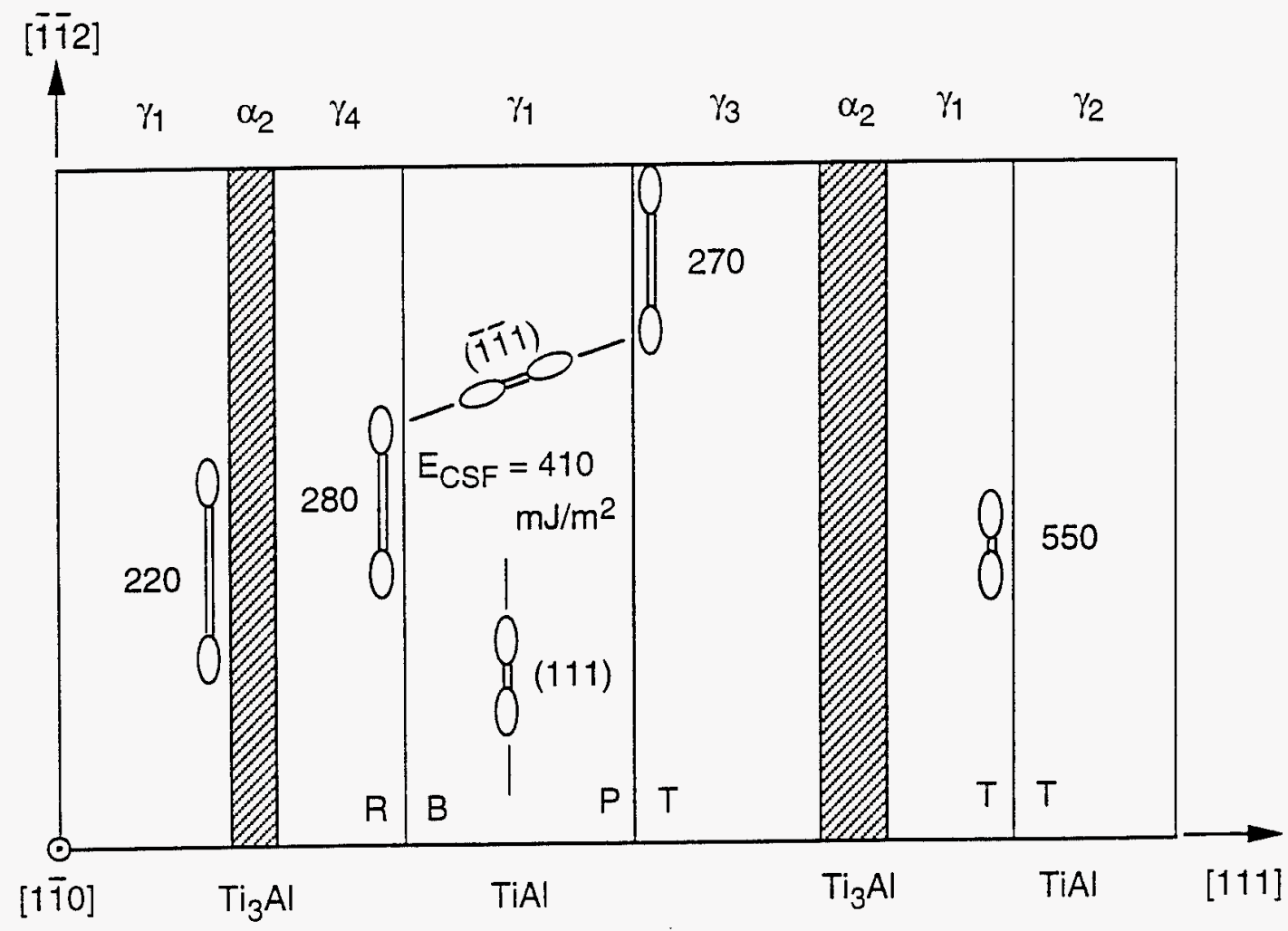

Fig. 6. CSF energies and dissociation of screw [1 $1 \overline{1} 0] / 2$ dislocations in PST crystals. 
According to the classical Peierls concept of dislocation mobility, the wider the planar dissociation configuration of a dislocation, the more mobile the dislocation is. In the case of $\{111\}<1 \overline{1} 0] / 2$ ordinary slip system in TiAl, Simmons et al. [17] found from their atomistic simulation study that the highest CSF energy caused the dislocation core to develop non-planar spreading, while the core structures associated with the lower energies were planar. Possible roles of various interfaces in the ordinary slip system can be discussed with the aid of Fig. 6 which schematically illustrates true-twin (TT, $\left.\gamma_{1} / \gamma_{2}\right)$, pseudo-twin (PT, $\left.\gamma_{1} / \gamma_{3}\right)$, rotational (RB, $\left.\gamma_{1} / \gamma_{4}\right)$, and $\alpha_{2} / \gamma\left(\mathrm{Ti}_{3} \mathrm{Al} / \mathrm{TiAl}\right)$ boundaries. Domain boundaries of other $\gamma / \gamma$-type that are roughly perpendicular to the (111) plane (Fig. 5) are neglected here for simplicity. Also neglected for now is the elastic inhomogeneity and anisotropy, and the presence of interfacial dislocations. The eiastic constants of $\gamma$-TiAl were used throughout PST crystals for dislocation width calculitions. The crystallographic orientation shown in Fig. 6 is with reference to the $\gamma_{1}$ domain.

A screw ordinary dislocation of Burgers vector, [1]0]/2, is dissociated on eithe: the (111) or (111) slip plane according to Eq. (2), where $E_{\mathrm{CSF}}=410 \mathrm{~mJ} / \mathrm{m}^{2}$ in the $\gamma_{1}$ bulk gives the equilibrium width of $\mathrm{w}_{\mathrm{C}}=0.29 \mathrm{~nm}$ [6]. The calculated values of $\mathrm{E}_{\mathrm{CSF}}$ at the $\gamma / \gamma$-type interfaces (the last column of Table I) and at the $\alpha_{2} / \gamma$ interface (Table II) are shown in Fig. 6, which schematically depicts relatively wider dissociations at interfaces. the widest being at the $\alpha_{2} / \gamma$ interface with $w_{C} \approx 0.55$ $\mathrm{nm}$. According to the simple criterion for the ease of gliding that the wider the dissociation configuration of a dislocation, the more mobile the dislocation is, the mobility of [110]/2 screw dislocation is expected to be slightly reduced along a true-twin boundary, but significantly enhanced along all other types of the interfaces.

Because of more complex dissociation configuration involving all three types of the planar faults, Eq. (3), the role of interfaces in the relative mobility of superdislocations is more complicated than of ordinary dislocations. As listed in Table I, while $\mathrm{E}_{\mathrm{APB}}$ and $\mathrm{E}_{\mathrm{CSF}}$ in the bulk of $\gamma$-phase are both reduced, by about a half. at pseudo-twin and $120^{\circ}$ rotational boundary interfaces, $\mathrm{E}_{\mathrm{SISF}}$ is increased about threefold.

As far as ordinary dislocations are involved, the enhanced mobility along these lamellar interfaces supports the notion of "channeled dislocation motion" [23] or "supersoft deformation mode" [12] in lamellar TiAl, which may be a contributing factor to the strong orientation dependence of yield strength in PST TiAl crystals [3]. Recent experimental results of offset displacement of the fiducial lines on deformation inhomogeneities [24] and in situ TEM observation of deformation-induced interface migration [25] are consistent with the inhomogeneous interfacial deformation.

\section{$\underline{\text { Slip-Twin-Interface Interactions }}$}

Interlayer distances of three different types are marked in Fig. 5 as $d_{L}, d_{D}$, and $d_{A}$, respectively, for $\gamma / \gamma$ lamellae, $\gamma / \gamma$ domains, and $\alpha_{2}$ lamellae. The initial state of internal stresses are created due to the distributions of interfacial misfit dislocations resulting from lattice parameter misfits at various semicoherent interfaces. These intrinsic interfacial dislocations have their Burgers vectors which are usually related to smallest partial dislocations in Eqs. (2-6). In the case of $\gamma / \gamma$ interfaces, interfacial dislocations form a network of screw character [26]. As illustrated in Fig. 6, after a screw (111)[110]/2 dislocation moves into $\alpha_{2} / \gamma_{1}, \mathrm{RB}$, or PT interface by cross-slip, it can interact with these intrinsic interfacial dislocations such a way that an extensive interfacial slip and/or migration occur.

When dislocations of edge or mixed types are involved in a dislocation pileup against these interfaces, stress concentration at the interfaces may reach a level sufficiently high for either initiation of slip or twinning into the adjacent domain leading to a Hall-Petch type relationship, or crack nucleation by the Stroh mechanism. This occurs mainly due to an accumulation of dislocation reaction products associated with the head of a pileup. These deformation-induced extrinsic interfacial dislocations (edge type) can alter the internal stresses significantly. Using HallPetch and Stroh mechanisms, Hazzledine and Kad [26] discussed the orientation dependent yield 
- and fracture stresses reported in PST TiAl crystals [3]. The highest yield strength achieved in $\gamma$ TiAl-based alloys, by refining the lamellar microstructure, is $971 \mathrm{MPa}$ at room temperature [27]. To interpret this result based on Hall-Petch relationship, Sun [28] introduced a dislocation multiple pileup model based on $d_{L}$ and $d_{G}$, the grain size. The intermediate lengths of $d_{D}$ and $d_{A}($ Fig. 5) and lamellar colony size have not been taken into consideration.

\section{Translamellar and Interfacial Fracture}

Once a microcrack is initiated on a (111) plane of $\gamma$-phase, which is of the lowest surface energy $\left(\gamma_{\mathrm{S}}=2.25 \mathrm{~J} / \mathrm{m}^{2}\right)$ in TiAl [29], it may propagate across a series of $\gamma / \gamma$ interfaces under the influence of mode- $\Pi$ and mode-III components of external loading applied to the coplanar

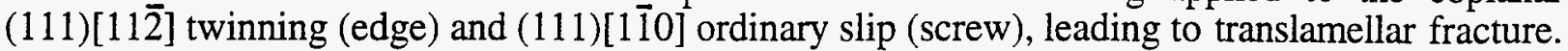
The effect of this mode mixity was illustrated in terms of crack-tip stress fields [20] and directly observed in an electron microscopy study [30].

Using the ideal cleavage energies, $G_{c},=2 \gamma_{s}$, calculated earlier [29] and the interfacial energies, $\Gamma_{i}$, given in Table I, one can evaluate interfacial fracture energy by using the relationship,

$$
\mathrm{G}_{\mathrm{i}}=\mathrm{G}_{\mathrm{c}}-\Gamma_{\mathrm{i}}-\mathrm{E}_{\mathrm{m}}
$$

where $E_{m}$ is the misfit energy estimated using the Frank and van der Merwe method [31] and the available lattice parameters of $\mathrm{TiAl}$ and $\mathrm{Ti}_{3} \mathrm{Al}$ [6]. The calculated results are summarized in Table $\Gamma$. Because of the approximations involved in determining the interfacial and misfit energies, the final interfacial fracture energies are only estimates. Nevertheless, these results give us a relative measure of interfacial fracture mode, indicating that fracture is easiest along $120^{\circ}$ rotational $\gamma / \gamma$ interfaces and most difficult along $\alpha_{2} / \gamma$ boundaries.

Table IV. Interfacial Fracture Energies in Two-Phase TiAl (in Units of $\mathrm{J} / \mathrm{m}^{2}$ )

\begin{tabular}{ccccr}
\hline Interface & $\mathrm{G}_{\mathrm{c}}$ & $\Gamma_{\mathrm{i}}$ & $\mathrm{E}_{\mathrm{m}}$ & $\mathrm{G}_{\mathrm{i}}$ \\
\hline$\gamma / \gamma$ & & & \\
$\mathrm{PT}\left(60^{\circ}\right)$ & 4.5 & 0.27 & & $\sim 4.2$ \\
$\mathrm{RB}\left(120^{\circ}\right)$ & 4.5 & 0.25 & 0.03 & 4.2 \\
$\mathrm{TT}\left(180^{\circ}\right)$ & 4.5 & 0.06 & & -4.4 \\
$\alpha_{2} / \gamma$ & 4.65 & 0.10 & 0.07 & 4.5 \\
\hline
\end{tabular}

At room temperature, single-phase $\gamma$-TiAl is very brittle, but fracture toughness $\left(\mathrm{K}_{\mathrm{Q}}\right)$ of twophase TiAl alloys is measured to be reasonably good, e.g., the critical stress intensity factor for Mode I crack of $K_{I C}=16-23 \mathrm{MPa} \sqrt{m}$ from fully lamellar microstructure [32], $\mathrm{K}_{\mathrm{Q}}=10-32 \mathrm{MPa} \sqrt{\mathrm{m}}$ from a variety of microstructures [33], and $\mathrm{K}_{\mathrm{Q}}>50 \mathrm{MPa} \vee \mathrm{m}$ from fine $\left(\mathrm{d}_{\mathrm{L}}=0.1-0.4 \mu \mathrm{m}\right)$ lamellar microstructures [34]. According to Booth and Roberts [35], the average stress intensity factor of $\gamma-\mathrm{TiAl}$ single crystals is $\mathrm{K}_{\mathrm{IC}}=1.0 \mathrm{MPa} / \mathrm{m}$, which is close to the theoretical values of $\mathrm{k}_{\mathrm{IC}}$ $=0.89$ and $1.04 \mathrm{MPa} V \mathrm{~m}$ for the $\{100\}$ and $(001)$ surfaces at $0 \mathrm{~K}$, respectively [20]. In singlephase $\gamma$-TiAl, experimental evidence of crack-tip slip and twinning $\left(\mathrm{K}_{\mathrm{Q}}>7 \mathrm{MPa} / \mathrm{m}\right)$ was analyzed in Ti-54 at. \% Al [36], and grain-boundary toughening $\left(\mathrm{K}_{\mathrm{Q}} \approx 10 \mathrm{MPa} / \mathrm{m}\right)$ was reported in Ti-50 at. \% Al [33]. Obviously, in two-phase TiAl alloys, the presence of various lamellar interfaces influences the crack-tip plasticity, which is strongly orientation dependent $[4,37]$, and therefore affecting translamellar and interfacial microcracking in the crack-tip region. Based on the 
calculated energies of surfaces and interfaces (Table IV), the tendency for translamellar $\left(\mathrm{G}_{\mathrm{C}}=4.5\right.$ $\mathrm{J} / \mathrm{m}^{2}$ for $\{111\}$ crack in $\gamma$-phase) or interfacial microcracking along the $\alpha_{2} / \gamma$ boundaries $\left(\mathrm{G}_{\mathrm{i}}=4.5\right.$ $\mathrm{J} / \mathrm{m}^{2}$ ) is the same. It is the mode mixity of the stress state at a head of the main crack that dictates the fracture toughness of a lamellar microstructure. The inverse relationship between the fracture toughness and the lamellar spacing $\left(\mathrm{d}_{\mathrm{L}}\right.$ and/or $\left.\mathrm{d}_{\mathrm{A}}\right)$ has been reported [32], and the coherency stresses may become significantly large at fine lamellar microstructure to an extent that they tend to prevent crack propagation across $\alpha_{2}$ lamellae [38].

\section{SUMMARY}

More common observation of the true-twin type interfaces in the lamellar microstructure and the propensity of deformation twinning, in two-phase $\mathrm{TiAl}_{-} \mathrm{Ti}_{3} \mathrm{Al}$ alloys, are consistent with the low value, $\Gamma_{\mathrm{T}}=60 \mathrm{~mJ} / \mathrm{m}^{2}$, of true-twin boundary energy. Planar fault energies at os zudo-twin and $120^{\circ}$ rotational interfaces are markedly different from their counterparts in the bulk o1 $\%$-phase, i.e., approximately, $\mathrm{E}_{\mathrm{APB}}$ and $\mathrm{E}_{\mathrm{CSF}}$ decreases by a half and $\mathrm{E}_{\mathrm{SISF}}$ increases by a threericld. Enhanced mobility of ordinary dislocations along $\alpha_{2} / \gamma$ and $\gamma / \gamma$ interfaces (except true twin boundaries) is predicted based on the reduced $E_{C S F}$ values. Though the differences are not large, interfacial fracture energies are estimated to be the highest for the $\alpha_{2} / \gamma$ lamellar boundary and the lowest for $120^{\circ}$ rotational $\gamma / \gamma$ boundary. The mode mixity plays an important role in the crack-tip plasticity by ordinary slip and true-twinning, leading to translamellar and interfacial fracture

\section{ACKNOWLEDGMENTS}

This research was sponsored by the Division of Materials Sciences, U.S. Department of Energy under contract number DE-AC05-960R22464 with Lockheed Martin Energy Research Corp. Authors thank J. H. Schneibel and C. T. Liu for reviewing and C. L. Dowker for preparing the manuscript.

\section{REFERENCES}

1. Gamma Titanium Aluminides, eds. Y.-W. Kim, R. Wagner, and M. Yamaguchi (TMS Symp. Proc., Warrendale, PA, 1995).

2. Fundamental Aspects of Gamma Titanium Aluminides, Symposium at TMS Annual Meeting, Feb. 10-12, 1997, Orlando (Papers to be published in Metall. Trans. A).

3. T. Fujiwara, A. Nakamura, M. Hosomi, S. R. Nishitani, Y. Shirai, and M. Yamaguchi, Phil. Mag. A 61, 591 (1990).

4. T. Nakano, T. Kawanaka, H. Y. Yasuda, and Y. Umakoshi, Mater. Sci. Eng. A 194, 43 (1995).

5. C. L. Fu and M. H. Yoo, Phil. Mag. Lett. 62, 159 (1990).

6. M. H. Yoo and C. L. Fu, Metall. Mater. Trans. A (in press).

7. C. McCullough, J. J. Valencia, C. G. Levi, and R. Mehrabian, Acta Met. 37, 1321 (1989).

8. P. Wang and V. K. Vasudevan, High-Temperature Ordered Intermetallic Alloys IV, eds. I. Baker, R. Darolia, J. D. Whittenberger, and M. H. Yoo (MRS Symp. Proc. Vol. 288, Pittsburgh, PA, 1993), p.229.

9. M. J. Blackburn, The Science and Technology and Applications of Titanium, Pergamon, Oxford, 1970, p. 633 .

10. Y.-W. Kim. Microstructure-Propertv Relationships in Titanium Aluminides and Alloys, eds. Y.-W. Kim and R. R. Boyer (TMS Symp. Proc., Warrendale, PA, 1991), p.91.

11. S. A. Jones and M. F. Kaufman, Acta Metall. Mater. 41 (1993) 387. 
" '12." S. Rao, C. Woodward, and P. M. Hazzledine, Defect-Interface Interactions, eds. E. P. Kvam, A. H. King, M. J. Mills, T. D. Sands, and V. Vitek (MRS Symp. Proc. Vol. 319, Pittsburgh, PA, 1994), p.285.

13. W. Wimmer, H. Krakauer, M. Weinert, and A. J. Freeman, Phys. Rev. B24, 864 (1981)

14. C. L. Fu and M. H. Yoo, Scr. Mater. 37, 1453 (1997).

15. C. Woodward and J. M. MacLaren, J. Mater. Res., 7 (1992) 1735.

16. M. H. Yoo, C. L. Fu, and J. K. Lee, Twinning in Advanced Materials, eds. M. H. Yoo and M. Wuttig (TMS Symp. Proc., Warrendale, PA, 1994), p.97.

17. J. P. Simmons, S. I. Rao, and D. M. Dimiduk, Phil. Mag. A 75, 1299 (1997).

18. C. L. Fu, J. Zou, and M. H. Yoo, Scr. Metall. Mater. 33, 885 (1995).

19. Y. Umakoshi and M. Yamaguchi, Phys. Stat. Sol. (a) 68, 457 (1981).

20. M. H. Yoo, J. Zou, and C. L. Fu, Mater. Sci. Eng. A 192/193, 14 (1995).

21. P. M. Hazzledine, B. K. Kad, H. L. Fraser, and D. M. Dimiduk, Intermetallic Matrix Composites II, eds. D. B. Miracle, D. L. Anton, and J. A. Graves (MRS Symp. Proc. Vol. 273, MRS, Pittsburg, PA, 1992), p. 81.

22. F. Appel and R. Wagner, Gamma Titanium Aluminides, eds. Y.-W. Kim, R. Wagner, and M. Yamaguchi (TMS Symp. Proc., Warrendale, PA, 1995), p. 231.

23. B. K. Kad, P. M. Hazzledine, and H. L. Fraser, High-Temperature Ordered Intermetallic Alloys IV, eds. I. Baker, R. Darolia, J. D. Whittenberger, and M. H. Yoo (MRS Symp. Proc. Vol. 288, Pittsburgh, PA, 1993), p.495.

24. B. K. Kad and R. Asaro, unpublished result, Univ. of California, San Diego, 1996.

25. L. M. Hsiung, A. J. Schwartz, and T. G. Nieh, Scr. Mater. 36, 1017 (1997).

26. P. M. Hazzledine and B. K. Kad, Mater. Sci. Eng. A 192/193, 340 (1995).

27. C. T. Liu, P. J. Maziasz, D. R. Clemens, J. H. Schneibel, V. K. Sikka, T. G. Nieh. J. L. Wright, and L. R. Walker, Gamma Titanium Aluminides, eds. Y.-W. Kim, R. Wagner, and M. Yamaguchi (TMS Symp. Proc., Warrendale. PA, 1995), p. 679.

28. Y. Q. Sun. High-Temperature Ordered Intermetallic Alloys-VII, eds. C. C. Koch. C. T. Liu. N. S. Stoloff, and A. Wanner (MRS Symp. Proc. Vol. 460, Pittsburgh, PA, 1997), p.109.

29. M. H. Yoo and C. L. Fu, Mater. Sci. Eng. A 153. 470 (1992).

30. F. Appel. U. Christoph. and R. Wagner, Phil. Mag. A 72, 341 (1995).

31. J. W. Mathews, Phil. Mag. 29, 797 (1974).

32. K. Chan and Y.-W. Kim, Acta Metall. Mater. 43, 439 (1995).

33. S. Mitao. S. Tsuyama, and K. Minakawa, Mater. Sci. Eng. A 143, 51 (1991).

34. C. T. Liu, J. H. Schneibel, P. J. Maziasz, J. L. Wright, and D. S. Easton, Intermetallics 4, 429 (1996).

35. A. S. Booth and S. G. Roberts, Acta Mater. 45, 1045 (1997).

36. I. Phan-Courson, Doctoral Thesis, University of Paris VI, 1993.

37. S. Yokoshima and M. Yamaguchi, Acta Mater. 44, 873 (1996).

38. P. M. Hazzledine, B. Shoykhet. and M. A. Grinfeld, Proc. David A. Smith Symposium on Boundaries and Interfaces in Materials, TMS Fall Meeting Sept. 14-18, 1997 (in press). 


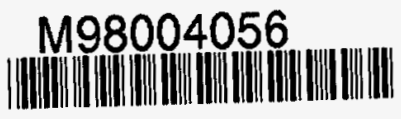

Report Number (14) ORNL/CP--96254
CONF-97120L--

Publ. Date (11) 199801

Sponsor Code (18) DOE/ER,XF

UC Category (19) $4 C-400$; DOEIER 